\title{
Improved but not normalized glucose counter-regulation during glucagon infusion in Type 1 (insulin-dependent) diabetes
}

\author{
I. Lager ${ }^{1}$, H.von Schenck ${ }^{2}$ and U.Smith ${ }^{1}$ \\ ${ }^{1}$ Department of Medicine II, University of Gothenburg, Sahlgren's Hospital, Gothenburg and \\ ${ }^{2}$ Department of Clinical Chemistry, University of Linköping, Linköping, Sweden
}

\begin{abstract}
Summary. Glucose counter-regulation during insulin-induced hypoglycaemia was studied in Type 1 diabetic patients without evidence of autonomic neuropathy and compared with that of a non-diabetic control group. The glucose recovery rate following hypoglycaemia was delayed in the diabetic compared with the control subjects and this was most pronounced for the initial, rapid phase of glucose increase (glucose increase in $15 \mathrm{~min}$, control: $1.1 \pm 0.1$ versus $0.4 \pm$ $0.1 \mathrm{mmol} / 1 ; p<0.01)$. The release of glucagon during hypoglycaemia was blunted in the diabetic patients (maximal plasma levels, control: $148 \pm 25$ versus $70 \pm 10 \mathrm{pg} / \mathrm{ml} ; p<$ 0.01 ). The adrenaline levels were also lower compared with the control subjects (maximal plasma levels, control: $7.23 \pm$
\end{abstract}

1.21 versus $3.27 \pm 0.87 \mathrm{nmol} / 1 ; p<0.05$ ). To evaluate the importance of the blunted glucagon response for the delayed glucose compensation, glucagon was infused during the hypoglycaemia. Overall glucose recovery rate was improved but did not return to normal. Consequently impaired glucagon release in the diabetic patients cannot alone explain impaired glucoregulation; the lower adrenaline levels and/or an effect of the previous glucose levels per se on hepatic glucose production are probably also of importance.

Key words: Glucose counter-regulation, hypoglycaemia, Type 1 diabetes, adrenaline, glucagon.
A reduced glucose recovery rate following hypoglycaemia in Type 1 (insulin-dependent) diabetic patients, even in the absence of a demonstrable neuropathy, was first reported by Lager et al. [1] and has subsequently been confirmed by several investigators $[2,3]$. The mechanisms for the delayed glucose compensation in diabetes are unclear. Decreased insulin clearance could be of importance [4], as well as the elevated blood glucose levels per se, in influencing hepatic glucose production [5]. Glucagon [6] and catecholamines [7, 8] have been ascribed a primary role in counteracting insulininduced hypoglycaemia. Cortisol and growth hormone, however, do not appear to play a major role in glucose compensation [6, 9]. Most investigators agree that glucagon release during hypoglycaemia is blunted in Type 1 diabetes [10-13], while catecholamine release has been reported to be similar to that of normal subjects in some $[4,14]$ but not all $[10,15]$ studies.

To evaluate the importance of glucagon, Type 1 diabetic patients were rendered hypoglycaemic and either glucagon or saline was infused during hypoglycaemia. The glucose recovery rate thus obtained was compared to that seen in an age- and weight-matched control group studied under the same conditions.

\section{Patients and methods}

\begin{abstract}
Patients
Seven patients with Type 1 diabetes (mean age 29 years, $82 \%-114 \%$ of ideal body weight) with a duration of diabetes ranging from 6 to 13 years (mean 9 years), and six age- and weight-matched control subjects (mean age 27 years, $89 \%-102 \%$ of ideal body weight) were studied during insulin-induced hypoglycaemia. Informed consent was obtained from all subjects and the study was approved by the hospital Ethical Committee. The patients were recruited from the Diabetic Outpatient Clinic and were considered to be well regulated on a combination of intermediate- and short-acting insulin two or three times daily (Insulin Monotard and Actrapid, Novo, Denmark; Insulatard and Velosulin, Nordisk, Denmark). Glycosylated haemoglobin $\left(\mathrm{HbA}_{1}\right)$ levels were between $7.1 \%$ and $10.1 \%$ (mean 8.6\%). Further clinical details are shown in Table 1 . None of the patients was on any medication other than insulin. The patients had no clinical or laboratory evidence of autonomic neuropathy. The presence of autonomic neuropathy was evaluated with the immediate heart-rate response to standing [16] and the heart-rate variation during deep breathing [17]; all were normal.
\end{abstract}

\section{Methods}

Hypoglycaemia was induced after an overnight fast. The diabetic patients took their regular insulin dose the day before but not on the morning of the study. Hypoglycaemia was induced twice in each pat- 
Table 1. Clinical characteristics of the subjects

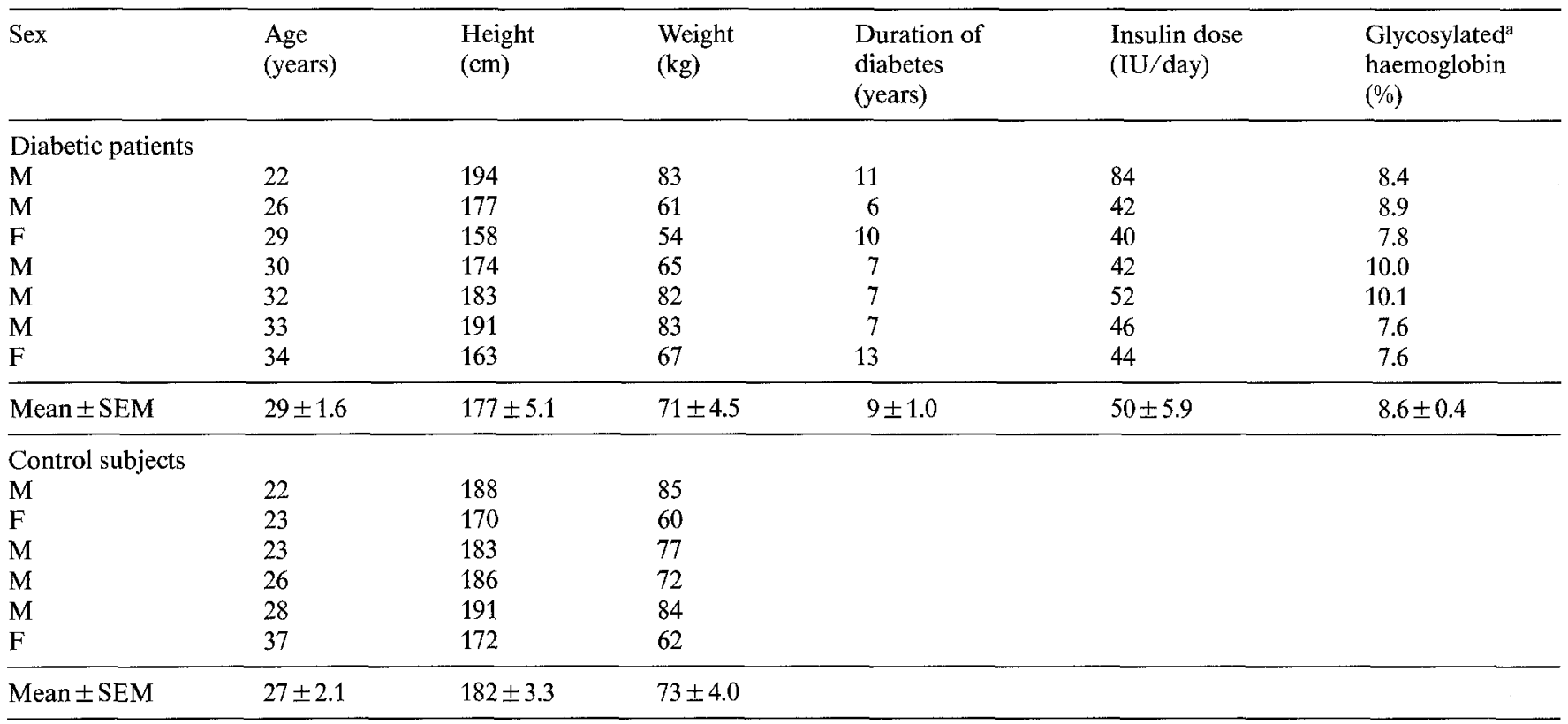

a Upper limit of normal for glycosylated haemoglobin is $7 \%$.

ient with at least 1 week between studies. Insulin (Actrapid, $0.15 \mathrm{U}$. $\mathrm{kg}^{-1} \cdot \mathrm{h}^{-1}$ ) was infused into an antecubital vein. Blood samples were collected from the contralateral arm. Blood glucose levels were followed every $5 \mathrm{~min}$ with a reflectometer (Reflomat, Clinicon International, Mannheim, FRG). When a glucose level of $2.0 \mathrm{mmol} / 1$ was reached, the insulin infusion was stopped. Thereafter glucose levels were followed every $5 \mathrm{~min}$ to determine the glucose nadir. Blood samples for the determination of blood glucose levels by a glucose oxidase technique (Kabi Diagnostics, Stockholm, Sweden) were collected before the insulin infusion, when the insulin infusion was stopped, at the glucose nadir (determined by reflectometer) and during the recovery period. Blood glucose levels shown hereafter are those obtained by the glucose oxidase technique.

When the insulin infusion was stopped, an IV infusion of either saline $(154 \mathrm{mmol} / \mathrm{l})$ or glucagon (Novo) was started in the diabetic patients. The glucagon infusion was commenced with an exponentially decreasing dose of $19 \mathrm{ng} \cdot \mathrm{kg}^{-1} \cdot \mathrm{min}^{-1}$ during the first $10 \mathrm{~min}$ followed by a constant infusion of $6 \mathrm{ng} \cdot \mathrm{kg}^{-1} \cdot \mathrm{min}^{-1}$ throughout the study period. The order of administration of either saline or glucagon. was randomly determined.

Blood samples were drawn for subsequent analyses of blood glucose, insulin, catecholamines and glucagon before the insulin infusions, at glucose nadir and at the indicated times after nadir.

Hypoglycaemia was induced once in the control subjects. The same procedures were followed as during the saline infusion in the diabetic patients.

Insulin was determined by radioimmunoassay using Phadeseph insulin-test (Pharmacia, Uppsala, Sweden) both in untreated sera from the control subjects and in the supernatant of polyethyleneglycol treated sera from diabetic subjects [18]. The insulin values from the control subjects were converted to free insulin values according to the method of Kizuya et al. [18] $(r=0.992)$. The intra-assay coefficient of variation at levels below $20.5 \mathrm{mU} / 1$ was $22.1 \%$, at $21-70.5 \mathrm{mU} / 1,4.7 \%$, and above $71 \mathrm{mU} / 1,2.8 \%$. The inter-assay coefficient of variation was $8.4 \%$ at $36 \mathrm{mU} / 1$.

Glucagon was assayed with antiserum E7 [19]. This antiserum, which recognized the carboxy-terminal region of glucagon, has been characterized with antiserum $30 \mathrm{~K}$ as reference [20]. Catecholamines were determined with an isotope technique [21].

\section{Statistical analysis}

Data are shown as mean \pm SEM. Statistical analyses included Student's t-test for paired or unpaired data, respectively, and linear regression analysis.

\section{Results}

\section{Glucose levels}

The fasting glucose levels immediately before the insulin infusion were similar on both occasions in the diabetic patients, but they were significantly higher than in the control subjects (control: $4.2 \pm 0.1$; diabetic (saline): $6.7 \pm 0.9$; diabetic (glucagon): $8.7 \pm 1.0 \mathrm{mmol} / 1 ; p<$ 0.01 ). The total insulin infusion time required to reach hypoglycaemia was longer in the diabetic compared with the control subjects (control: $35 \pm 4$; diabetic (saline): $63 \pm 10 \mathrm{~min} ; p<0.01)$. The insulin infusion time was also longer in the diabetic patients during glucagon infusion than during saline infusion (diabetic (glucagon): $84 \pm 11 \mathrm{~min}$ ); however, the difference was not significant. The glucose levels when the insulin infusion was discontinued were similar in both the control and diabetic groups (control: $1.6 \pm 0.1$, diabetic (saline): $1.7 \pm 0.2$, diabetic (glucagon): $1.9 \pm 0.3 \mathrm{mmol} / \mathrm{l}$ ). After stopping the insulin infusion the glucose levels showed a slight and transient decrease in the control and a more marked decrease in the diabetic group receiving saline infusion (Fig.1). The lowest glucose levels were also seen later in the diabetic group (control: 1.5 \pm $0.1 \mathrm{mmol} / 1$ after $13 \pm 1 \mathrm{~min}$, diabetic (saline): $1.3 \pm$ 


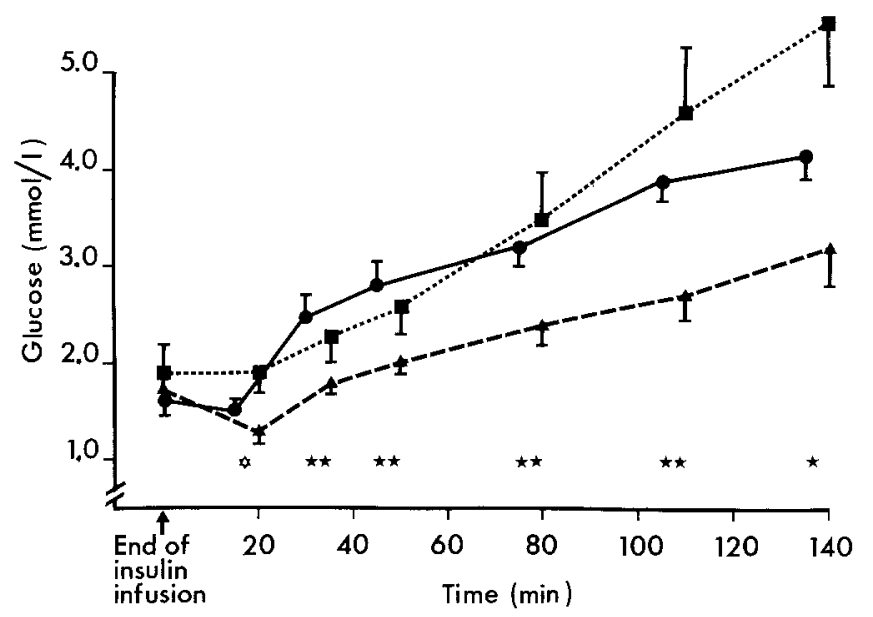

Fig.1. Glucose levels in control subjects (-) and diabetic patients during infusion of saline $(\boldsymbol{\Delta}---\mathbf{\Delta})$ or during glucagon infusion $(\square--$ - Results are mean $\pm \mathrm{SEM} ; \star p<0.05, \star \star p<0.01$ for control versus diabetic subjects receiving saline; $p<0.05$ for control versus diabetic subjects receiving glucagon

$0.1 \mathrm{mmol} / 1$ after $22 \pm 2 \mathrm{~min}$ ). However glucose levels in the diabetic patients receiving glucagon infusion did not decrease further after stopping the insulin infusion, but remained unchanged $(1.9 \pm 0.2 \mathrm{mmol} / 1$ after $19 \pm$ $3 \mathrm{~min})$. The lowest glucose levels measured were therefore higher in this group than in control subjects $(p<$ 0.05; Fig. 1).

After reaching the nadir the initial glucose increase was rapid in the control subjects but significantly slower in the diabetic group (increase in $15 \mathrm{~min}$, control: $1.1 \pm$ 0.1 ; diabetic (saline): $0.4 \pm 0.1$; diabetic (glucagon): $0.4 \pm 0.2 \mathrm{mmol} / 1 ; p<0.01$ ). The glucose levels after nadir were significantly lower in the diabetic patients receiving saline but not glucagon infusion compared to the control subjects (Fig. 1).

\section{Free insulin levels}

Fasting free insulin levels were similar in all groups (control: $14 \pm 4$; diabetic (saline): $10 \pm 3$; diabetic (glucagon): $14 \pm 5 \mathrm{mU} / 1$ ). When the insulin infusion was stopped insulin levels were significantly higher in the control than in the diabetic subjects (control: $151 \pm 8$; diabetic (saline): $117 \pm 14$; diabetic (glucagon): $123 \pm$ $14 \mathrm{mU} / 1 ; p<0.05$ ). However, the insulin levels at glucose nadir and subsequently during the compensatory period were not significantly different (Fig. 2). The initial half-time of the insulin disappearance was prolonged in the diabetic patients compared with control subjects (control: $7.8 \pm 0.8$; diabetic (saline): $13.1 \pm 1.2$; diabetic (glucagon): $12.2 \pm 1.6 \mathrm{~min} ; p<0.01$ ). There was no correlation between the insulin levels at the time the insulin infusion was stopped or at glucose nadir and the glucose recovery rate either in the control or diabetic subjects.

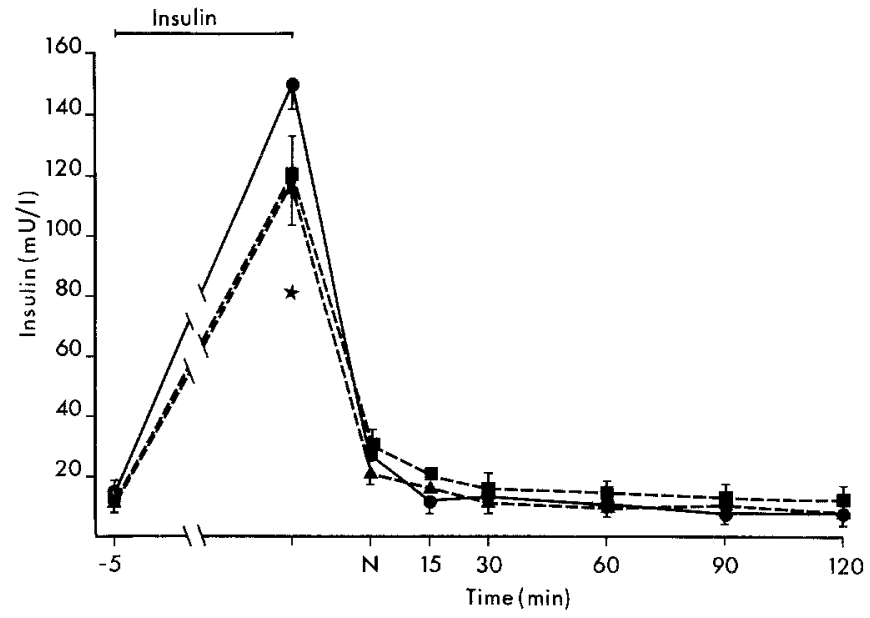

Fig. 2. Plasma levels of free insulin in control ( $\longrightarrow$ ) and diabetic subjects receiving saline $(\boldsymbol{\Delta}---\mathbf{\Delta})$ and glucagon infusion ( $--\infty$ ). Results are mean \pm SEM; $\star p<0.05$ for control and diabetic subjects receiving saline and glucagon. $N=$ glucose nadir

\section{Glucagon levels}

Fasting glucagon levels were similar in all groups (control: $53 \pm 4$; diabetic (saline): $43 \pm 4$; diabetic (glucagon): $51 \pm 6 \mathrm{pg} / \mathrm{ml}$ ). In the control subjects, a striking elevation of plasma glucagon was seen with maximal levels at glucose nadir $(148 \pm 25 \mathrm{pg} / \mathrm{ml})$. In the diabetic patients, however, the glucagon increase during hypoglycaemia was significantly lower with maximal plasma levels at glucose nadir of only $70 \pm 10 \mathrm{pg} / \mathrm{ml}(p<0.01)$. In the glucagon infusion group high levels had already been reached by the time of glucose nadir (284 \pm $37 \mathrm{pg} / \mathrm{ml}$ ) and they remained elevated thereafter (Fig. 3).

A negative correlation was found between duration of diabetes and the maximal glucagon increase during hypoglycaemia $(r=-0.73, p<0.05$; Fig. 4$)$. There was however no significant correlation between the glucagon levels at glucose nadir and the glucose recovery rate, nor between the duration of diabetes and glucose compensation.

\section{Catecholamine levels}

Catecholamines were measured in the control and diabetic subjects during saline infusion. The adrenaline levels before the insulin infusion were similar (control: $0.13 \pm 0.02$; diabetic: $0.23 \pm 0.07 \mathrm{nmol} / 1$ ). Plasma adrenaline increased dramatically during hypoglycaemia with maximal levels being reached at glucose nadir both in the control and diabetic subjects $(7.23 \pm 1.21$ versus $3.27 \pm 0.87 \mathrm{nmol} / \mathrm{l})$. The adrenaline levels at glucose nadir, as well as the maximal individual adrenaline increase, were significantly higher in the control than in the diabetic subjects $(p<0.025$; Fig. 4$)$. 

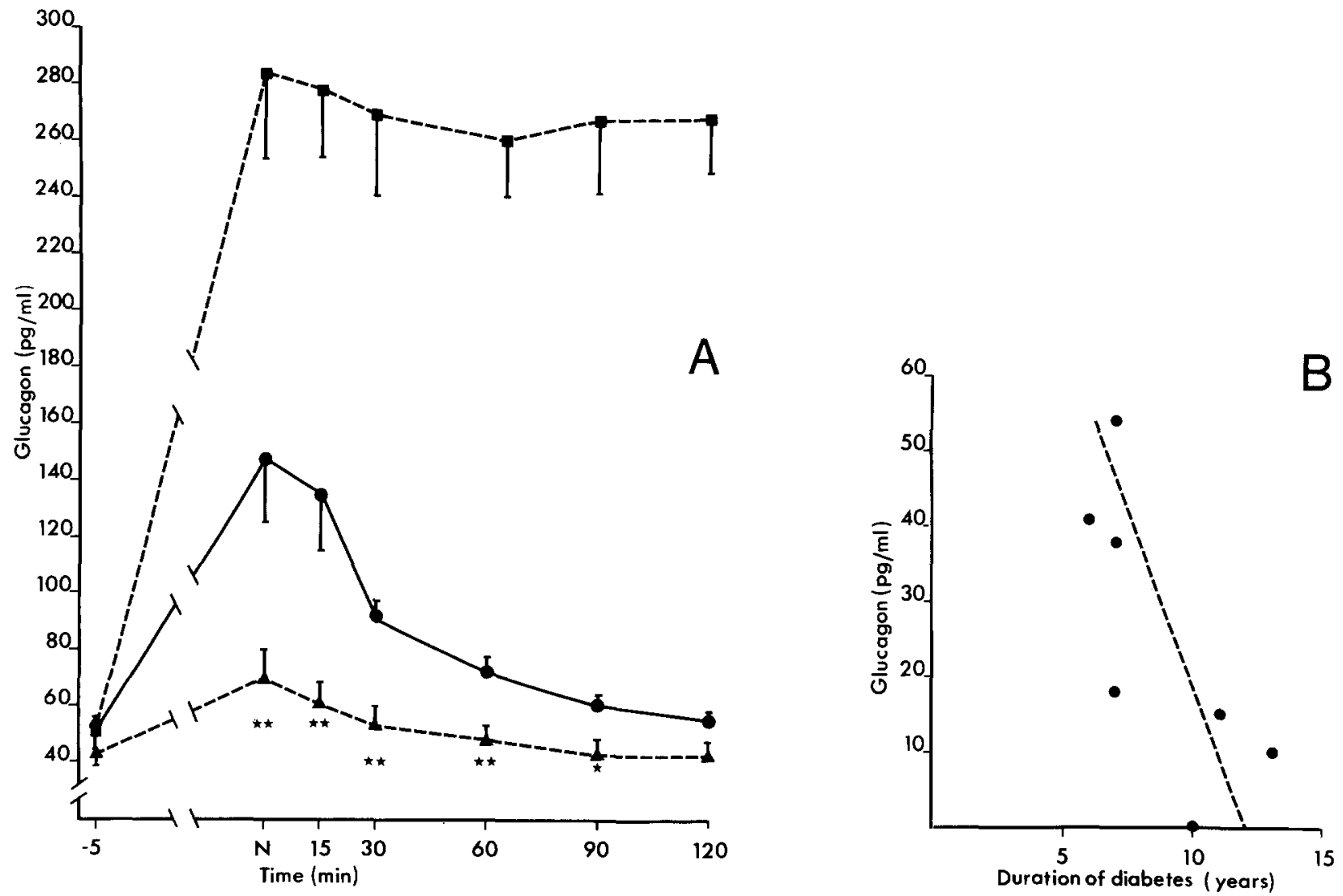

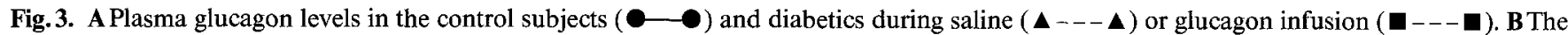
relationship between duration of diabetes and maximal glucagon increase during hypoglycaemia $(r=-0.76, p<0.05)$. Results are mean \pm SEM; $\star p<0.05, \star \star p<0.01$ for control and diabetic subjects receiving saline. $\mathrm{N}=$ glucose nadir

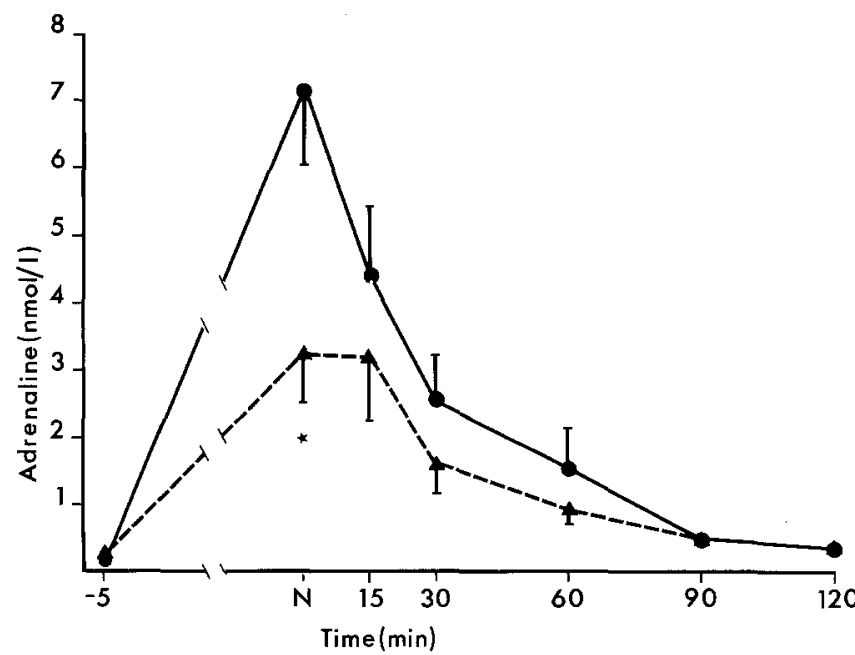

Fig.4. Plasma adrenaline levels in the control (-) and diabetic subjects $(\mathbf{\Lambda}--\mathbf{\Delta})$ receiving saline infusions. Results are mean \pm $\mathrm{SEM} ; \star p<0.025 . \mathrm{N}=$ glucose nadir

There was no significant difference in the maximal noradrenaline increase during hypoglycaemia between control and diabetic subjects (control $1.83 \pm 0.52$ versus $1.29 \pm 0.30 \mathrm{nmol} / 1)$. No correlation was found between the duration of diabetes and maximal catecholamine levels during hypoglycaemia, nor between the catecholamine levels at glucose nadir and the recovery rate.

\section{Discussion}

A delayed spontaneous glucose recovery rate following hypoglycaemia in the diabetic patients compared with control subjects was confirmed in this study [1-3, 5, 22]. The aim was to evaluate whether the blunted glucagon response regularly found in Type 1 diabetes during hypoglycaemia $[10-12,23,24]$ could, by itself, explain the delayed glucose compensation previously suggested from studies in healthy subjects [6]. The glucose recovery rate was indeed improved, but did not return to normal, following the infusion of glucagon in the diabetic subjects. Our data are in conflict with those in the recent report by Bolli et al. [25]; in that study glucagon was also infused in Type 1 diabetic subjects following insulininduced hypoglycaemia. In contrast to our findings, Bolli et al. [25] concluded that glucagon infusion completely normalized the glucose recovery following insulin-induced hypoglycaemia. This discrepancy can probably be explained by the differences in experimental design. The insulin infusion time to produce hypoglycaemia used by Bolli et al. was fixed irrespective of the blood glucose levels [25]; it is therefore difficult to compare directly with the present study. The higher peripheral glucagon levels reached in that study [25] and the start of the glucagon infusion at a higher blood glucose level than in the present study also make comparisons difficult. 
The glucagon release during hypoglycaemia does not seem to be dependent on adrenergic [26-30] or cholinergic [29, 30] stimulation but rather on the blood glucose level per se. The blunted glucagon response to hypoglycaemia in Type 1 diabetic patients found in the present and other studies [10-13] is therefore probably due to a defect in the A-cell glucoreceptor. This defect seems to be progressive as a negative correlation between diabetes duration and maximal glucagon response to hypoglycaemia exists [25, 31].

The lower adrenaline levels found in the present study in the diabetics during hypoglycaemia have also been found previously in some [15,32], but not all [4], reports. Release of adrenaline during hypoglycaemia is under the control of the central nervous system [33]. As previously pointed out, no evidence of autonomic neuropathy was found in the diabetics with the tests used and, in support of this, the maximal noradrenaline increase during hypoglycaemia was not significantly different between the control and diabetic subjects. The impaired release of adrenaline in the diabetics could therefore be due to an altered sensitivity of the glucoreceptors of the central nervous system.

The glucagon levels at glucose nadir following glucagon infusion were probably within the physiological range in the portal vein as the portal-peripheral glucagon ratio is about $1.7[34,35]$. Subsequently however, the glucagon levels were higher in the diabetic patients than in the normal subjects. An immediate effect of the glucagon infusion in the diabetic patients is evident as the glucose levels did not decrease further after the insulin infusion had been stopped in contrast to the situation with the saline infusion. Infusion of glucagon increased the overall rate of glucose recovery but did not completely restore the initial rate of glucose compensation. This could be due to an inhibitory effect of the elevated blood glucose levels per se on hepatic glucose production [5], as the patients were not optimally treated but remained on their regular treatment regimen until the studies. Another contributing factor could be the impaired adrenaline response as catecholamines appear essential for glucose production during insulin-induced hypoglycaemia, even when the release of glucagon is normal [36].

A delayed insulin clearance has been found in diabetic patients with insulin antibodies [25] and this could consequently be of importance for the glucose compensation. The initial half-time of insulin disappearance after the end of the insulin infusion was prolonged in the diabetic compared with the controls. However the levels of free insulin at glucose nadir, and subsequently during the compensatory period, were similar in the two groups. Thus the occurrence of insulin antibodies does not seem to be of any importance for delayed glucose recovery with the present experimental design. Additionally, no correlation was found between the insulin infusion time and the glucose recovery rate; this argues against a significant effect of the length of the insulin infusion on glucose compensation.
In conclusion, the present study shows the importance of a blunted glucagon response for delayed glucose compensation following hypoglycaemia in Type 1 diabetic patients as also recently reported $[24,25]$. The impaired release of glucagon alone could not, however, explain the impaired glucoregulation: the concomitant reduction of adrenaline release and/or an effect of elevated blood glucose levels in the diabetic patients appear to be of importance as well.

Acknowledgements. The excellent technical assistance of U. Skredsvik, R.N. is gratefully acknowledged. Financial support was given by the Swedish Medical Research Council (project 03506) and the Swedish Diabetes Association.

\section{References}

1. Lager I, Blohmé G, Smith U (1979) Effect of cardioselective and non-selective $\beta$-blockade on the hypoglycaemic response in insulin-dependent diabetics. Lancet 1: 458-462

2. Viberti GC, Keen H, Bloom SR (1980) Beta blockade and diabetes mellitus: Effect of oxprenolol and metoprolol on the metabolic, cardiovascular, and hormonal response to insulin-induced hypoglycaemia in insulin-dependent diabetics. Metabolism 29: 873-879

3. Bolli G, Calabrese G, DeFeo P, Compagnucci P, Zega G, Angeletti G, Cartechini MG, Santeusanio F, Brunetti P (1982) Lack of glucagon responsc in glucose counter-regulation in Type I (insulindependent) diabetics: absence of recovery after prolonged optimal insulin therapy. Diabetologia 22: 100-105

4. Hilsted J, Madsbad S, Krarup T, Sestoft L, Christenson NI, Tronier B, Galbo H (1981) Hormonal, metabolic, and cardiovascular responses to hypoglycemia in diabetic autonomic neuropathy. Diabetes 30: 626-633

5. Lager I, Blohmé G, von Schenck H, Smith U (1982) Importance of glucose control for the recovery from hypoglycemia in insulin-dependent diabetics. Diabetes 31:771-775

6. Rizza RA, Cryer PE, Gerich JE (1979) Role of glucagon, catecholamines, and growth hormone in human glucose counterregulation. J Clin Invest 64: 62-71

7. Garber AJ, Cryer PE, Santiago JV, Haymond MW, Pagliara AS, Kipnis DM (1976) The role of adrenergic mechanisms in the substrate and hormonal response to insulin-induced hypoglycaemia in man. J Clin Invest 58: 7-17

8. Gerich J, Cryer P, Rizza R (1980) Hormonal mechanisms in acute glucose counterregulation: the relative roles of glucagon, epinephrine, norepinephrine, growth hormone, and cortisol. Metabolism 29: 1164-1175

9. Feldman JM, Plonk JW, Bivens CH (1975) The role of cortisol and growth hormone in the counter-regulation of insulin-induced hypoglycaemia. Horm Metabol Res 7: 378-381

10. Lager I, Jagenburg R, von Schenk H, Smith U (1980) Effect of beta-blockade on hormone release during hypoglycaemia in insulindependent diabetics. Acta Endocrinol (Copenh) 95: 364-371

11. Gerich JE, Langlois M, Noacco C, Karam JH, Forsham PH (1973) Lack of glucagon response to hypoglycaemia in diabetes: evidence for an intrinsic pancreatic alpha cell defect. Science 182: 171-173

12. Benson JW, Johnson DG, Palmer J, Werner PL, Ensinck JW (1977) Glucagon and catecholamine secretion during hypoglycaemia in normal and diabetic man. J Clin Endocrinol Metab 44: $459-464$

13. Campbell LW, Kraegen EW, Lazarus L (1977) Defective blood glucose counterregulation in diabetics is a selective form of autonomic neuropathy. Br Med J 2: 1527-1529

14. Santiago JV, Clarke WL, Shah SD, Cryer PE (1980) Epinephrine, norepinephrine, glucagon, and growth hormone release in association with physiological decrements in the plasma glucose con- 
centration in normal and diabetic man. J Clin Endocrinol Metab 51: $877-883$

15. Popp DA, Shah SD, Cryer PE (1982) Role of epinephrine-mediated $\beta$-adrenergic mechanisms in hypoglycaemic glucose counterregulation and posthypoglycemic hyperglycaemia in insulin-dependent diabetes mellitus. J Clin Invest 69: 315-326

16. Ewing DJ, Campbell I, Murray A, Nielson JMM, Clarke BF (1978) Immediate heart-rate response to standing: simple test for autonomic neuropathy in diabetes. Br Med J 1: 145-147

17. Mackay JD, Page M McB, Cambridge J, Watkins PJ (1980) Diabetic autonomic neuropathy. The diagnostic value of heart monitoring. Diabetologia 18: 471-478

18. Kuzuya H, Blix PM, Horwitz DL, Steiner DF, Rubenstein AH (1979) Determination of free and total insulin and C-peptide in insulin-treated diabetics. Diabetes 26: 22-29

19. von Schenck H (1977) Production and characterization of an antiserum against pancreatic glucagon. Clin Chim Acta 80: 455-463

20. von Schenck H, Nilsson O (1981) Radioimmunoassay of extracted glucagon compared with three non-extraction assays. Clin Chim Acta 109: 183-191

21. Engelman K, Portnoy B (1970) A sensitive double-isotope derivate assay for norepinephrine and epinephrine. Circ Res 26: 53-55

22. Polonsky K, Bergenstal R, Pons G, Schneider M, Jaspan J, Rubenstein A (1982) Relation of counterregulatory responses to hypoglycaemia in Type I diabetics. N Engl J Med 307: 1105-1112

23. Hilsted J, Madsbad S, Krarup T, Heding LG, Sestoft L (1980) Metabolic responses to hypoglycemia in juvenile diabetics. Acta Med Scand 639:25-28

24. Madsbad S, Hilsted J, Krarup R, Sestoft L, Christensen NJ, Faber OK, Tronier B (1982) Hormonal, metabolic and cardiovascular responses to hypoglycaemia in Type I (insulin-dependent) diabetes with and without residual B cell function. Diabetologia 23: 499-503

25. Bolli G, De Feo P, Compagnucci P, Cartechini MG, Angeletti G, Santeusanio F, Brunetti P, Gerich J (1983) Abnormal glucose counterregulation in insulin-dependent diabetes mellitus. Diabetes 32: 134-141

26. Palmer JP, Henry DP, Benson JW, Johnson DG, Ensinck JW (1976) Glucagon response to hypoglycaemia in sympathectomized man. J Clin Invest 57: 522-525
27. Walter RM, Dudl RJ, Palmer JP, Ensinck JW (1974) The effect of adrenergic blockade on the glucagon responses to starvation and hypoglycaemia in man. J Clin Invest 54: 1214-1220

28. Ensinck JW, Walter RM, Palmer JP, Brodowns RG, Campbell RG (1976) Glucagon responses to hypoglycaemia in adrenalectomized man. Metabolism 25: 227-232

29. Palmer JP, Werner PL, Hollander P, Ensinck JW (1979) Evaluation of the control of glucagon secretion by the parasympathetic nervous system in man. Metabolism 28: 549-552

30. Corrall RM, Frier BM (1979) Acute hypoglycaemia in man: neural control of pancreatic islet cell function. Metabolism 30: 160-164

31. Patel DG (1983) Lack of glucagon response to hypoglycaemia in long-term experimental diabetic rats. Diabetes 32:55-60

32. Hoeldtke R, Boden G, Shuman C, Owen O (1982) Reduced epinephrine secretion and hypoglycaemic unawareness in diabetic autonomic neuropathy. Ann Intern Med 96: 459-462

33. Otsuka K, Assaykeen TA, Goldfien A, Ganong WF (1970) Effect of hypoglycaemia on plasma renin activity in dogs. Endocrinology $87: 1306-1317$

34. Blackard WG, Nelson NC, Andrews SS (1972) Portal and peripheral vein immunoreactive glucagon concentrations after arginine or glucose infusion. Diabetes 23: 199-202

35. Dencker H, Hedner P, Holst J, Tranberg K-G (1975) Pancreatic glucagon response to an ordinary meal. Scand J Gastroenterol 10 : $471-474$

36. Sacca L, Perez G, Carteni G, Rengo F (1977) Evaluation of the role of the sympathetic nervous system in the glucoregulatory response to insulin-induced hypoglycaemia in the rat. Endocrinology 101: 1016-1022

Received: 21 April 1983

and in revised form: 2 March 1984

Professor Ulf Smith

Department of Medicine II

Sahlgren's Hospital

S-413 45 Gothenburg

Sweden 